\title{
Molecular Dynamics in the Study and Development of Molecu- larly Imprinted Materials - Status Quo, Quo Vadis?
}

\author{
Ian A. Nicholls ${ }^{1, *}$, Kerstin Golker ${ }^{1}$ and Jesper G. Wiklander ${ }^{1}$ \\ 1 Linnaeus University Centre for Biomaterials Chemistry, Bioorganic and Biophysical Chemistry Laboratory, \\ Department of Chemistry and Biomedical Sciences, Linnaeus University, SE-391 82 Kalmar, Sweden; \\ ian.nicholls@lnu.se; kerstin.golker@lnu.se; jesper.wiklander@lnu.se \\ * Correspondence: ian.nicholls@lnu.se
}

\begin{abstract}
The past two decades have witnessed the introduction of and then a steady increase in the use of computational techniques in the study and development of molecularly imprinted polymers (MIPs). Molecular dynamics (MD) based studies have had a significant role in this development as they can provide insights concerning the mechanisms governing the molecular level events underlying MIP synthesis and MIP-ligand interactions and can be used for the identification of preferred monomer compositions and for the prediction of MIP properties. We here review the role that MD has played in the development of molecular imprinting and examine the different types of MD strategies that have been used, including their advantages and challenges. Recent trends in the application of MD to the study of MIPs are presented, along with a perspective on the future importance of MD-based studies for the development of molecular imprinting science and technology.
\end{abstract}

Keywords: computational chemistry; fragment screening; MD; MIP; molecular dynamics; molecular imprinting; molecularly imprinted polymer; simulation; template

\section{Introduction}

Molecular imprinting science and technology [1-12] has undergone an extended period of growth, largely driven by the demonstration of molecularly imprinted polymer (MIP)-ligand recognition properties comparable to those of antibodies [13] and the relative physical and chemical stability of MIPs [14]. These observations raised awareness of the possibility to use MIPs in applications requiring selective molecular recognition [1523]. This development has been sustained by the increasing use of MIPs in applications ranging from sensing and separation to catalysis and therapeutics, and the commercialized production of imprinted materials [24,25].

While the molecular imprinting concept is in principle simple, Figure 1, the underlying molecular level events are many and complex [26]. Attempts to elucidate the molecular level mechanisms for MIP synthesis and MIP-ligand recognition, and to rationally design MIPs, have been significant for the development of the field $[4,5]$. These efforts have been facilitated by the introduction of a range of methods for the study and design of MIPs and for the development of novel polymer compositions and formats. Prior to the introduction of computational techniques into the field, researchers had explored the use of various theoretical treatments [27-29], combinatorial polymer synthesis approaches $[30,31]$ and various spectroscopy-based studies [32-35]. It was, however, with the introduction of computational chemistry into the molecular imprinting field, particularly when used together with experimental studies, that significant interest in rational MIP design and understanding of molecular level details of MIP systems began to evolve, as can be followed through a series of reviews of the area over the period [36-49]. 

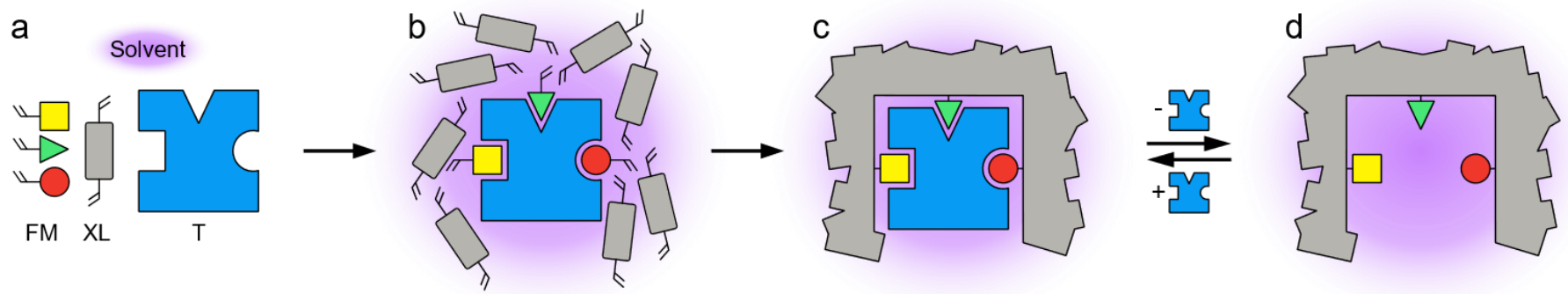

Figure 1. Schematic description of the different stages in the molecular imprinting process. (a) The main polymer components: template (T), functional monomers (FM) and cross-linking monomer (XL); (b) Pre-polymerization mixture; (c) After polymerization; (d) After template removal. Reproduced from [48].

The increased use of computational chemistry for better understanding the various aspects of the molecular imprinting process and for the design of novel MIPs has been driven by the establishment of more powerful computers, better theoretical descriptors, and purpose-oriented software. Collectively, these developments have, and continue to, pave the way for more precise and efficient modeling of molecular level structure and interactions in molecular imprinting systems, as reflected in the growing numbers of publications deploying computational chemistry [48]. Three broad classes of computational methods have been applied to the study and development of aspects of the molecular imprinting process and for understanding specific MIP systems: quantum mechanicsbased studies, statistical studies (most notably multivariate analysis) and molecular mechanics-based molecular dynamics studies [48]. With respect to MIP design and a broader understanding of the molecular-level mechanisms underlying the various stages of the molecular imprinting process, it is molecular dynamics-based studies that can be argued to have had, to this point in time, the greatest impact on molecular imprinting, and is a trend that continues, Figure 2. This development has arisen due to the capability to model complete systems with multiple examples of components in experimentally relevant stoichiometries, together with a documented capacity for validation or comparison with experimental studies and has resulted in a variety of studies for prognostic or diagnostic purposes [48].

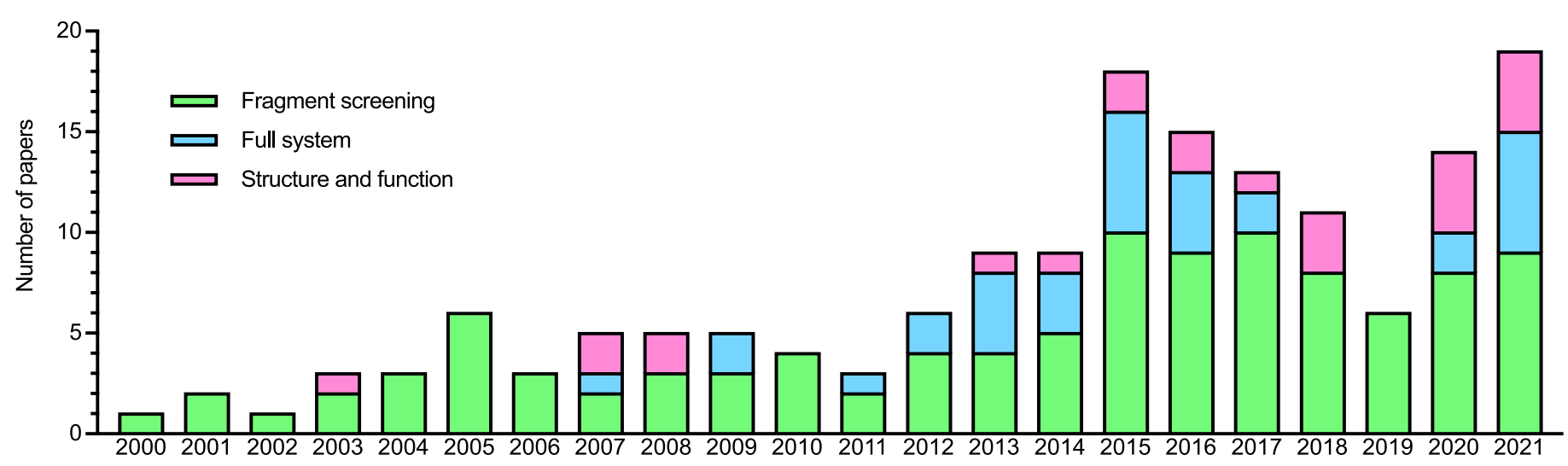

Figure 2. Number of published papers where MD simulations have been applied to molecular imprinting systems in order to either select MIP components (fragment screening), perform comprehensive studies of pre-polymerization interactions (full system) or create polymer models (structure and function).

Here we present a review of the establishment, development, current status and projected future (status quo, quo vadis?) of MD-studies in the molecular imprinting field. This review covers, and illustrates with examples from seminal studies, from the initial simulated annealing-based studies pioneered by the Piletsky group [50] and the broader use 
of fragment-screening-like [51,52] studies for ranking candidate monomers through to the introduction of full system all-atom studies for diagnostic and prognostic purposes pioneered by the Mizaikoff and Nicholls groups [53,54], all with a primary focus in the interaction of a number of pre-polymerization mixture components. The subsequent application of MD-studies for understanding or predicting molecular recognition phenomena in MIP systems through, most notably, site modeling and theoretical docking of ligands with in silico MIP-recognition sites is presented, together with a projection of the importance of MD-based techniques for the future of the molecular imprinting field.

\section{Fragment screening-like simulations of template-monomer interactions}

Since the ability of a MIP to selectively recognize and bind an analyte is derived from the complexes formed between template and functional monomers in the pre-polymerization solution, researchers have simulated this process in attempts to select the most appropriate monomer for a given template. In 2001 Piletsky and co-workers described a method for screening the template ephedrine against a library of 20 functional monomers [50]. The method has since been successfully applied in a range of studies [55-103]. In this protocol [94], an initial scoring function based on a Leapfrog-algorithm is followed by an MD-based annealing simulation, Figure 3. In the scoring step, interaction points on the template are identified based on electronic, steric, and lipophilic properties (colored crosses in Figure 3a) and the monomers in the library are then rotated around these points and interaction energies are calculated. Next, the template is placed in a virtual box saturated with the monomer(s) identified in the scoring step followed by an annealing simulation using MD. Finally, the system is energy minimized and the complexes formed are examined to determine a suitable monomer-template ratio, Figure $3 b$.

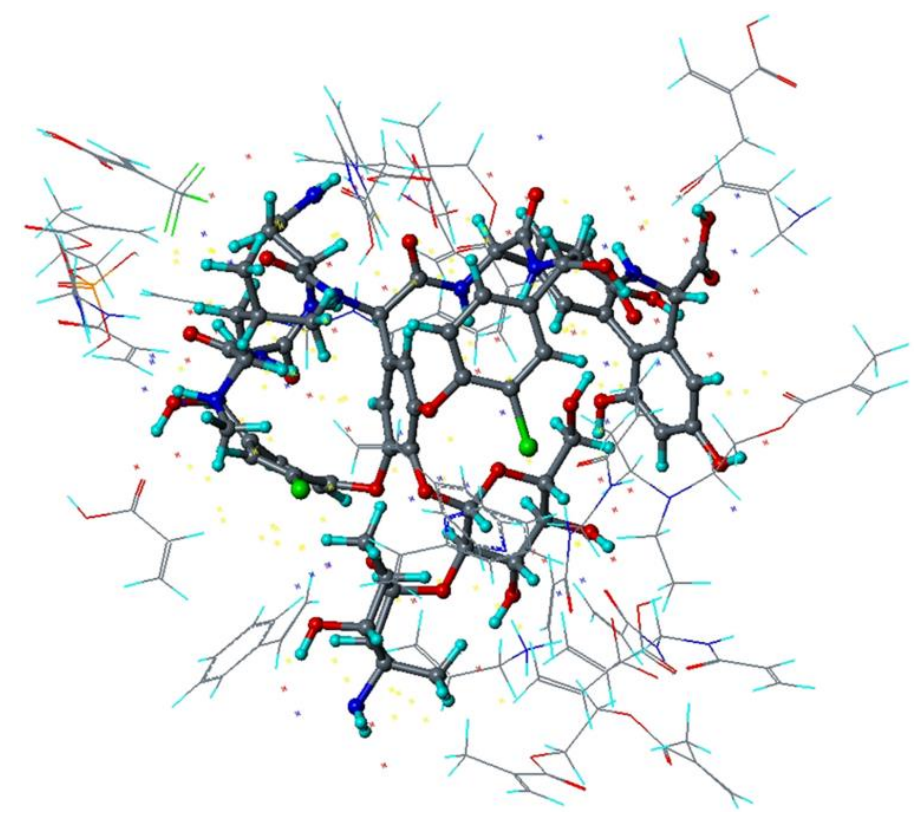

(a)

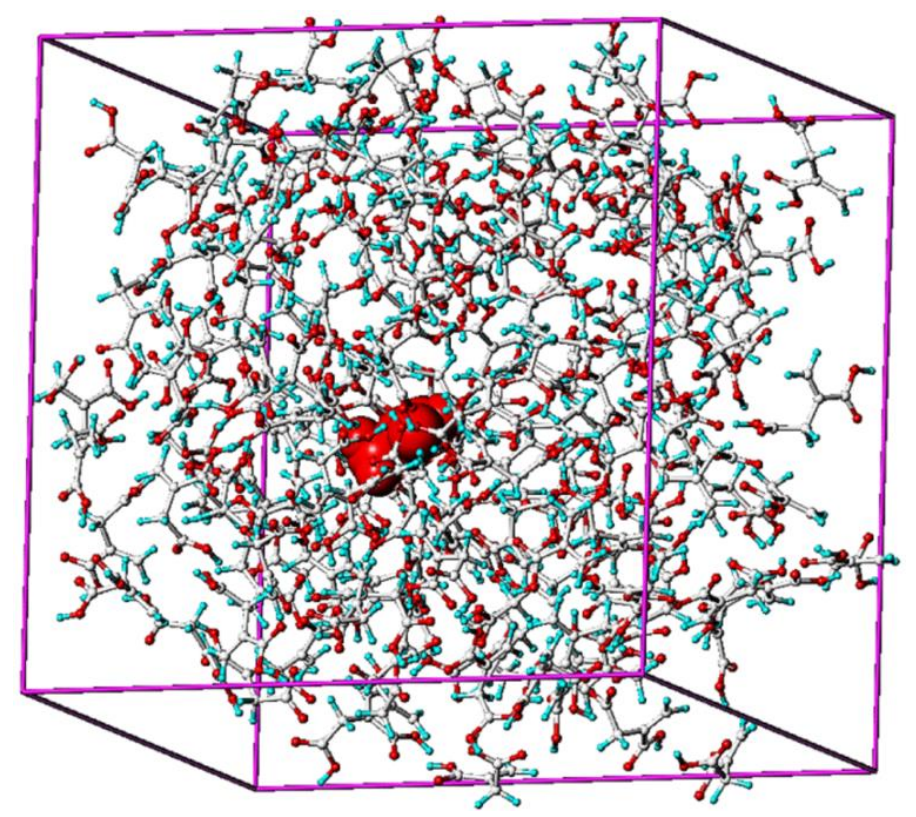

(b)

Figure 3. Monomer screening as described by Piletsky and co-workers: (a) Vancomycin surrounded by different functional monomers after screening. Reproduced from [42] with permission from Elsevier. (b) Acetamide (template, in red) surrounded by itaconic acid molecules (functional monomer) after an annealing simulation and energy minimization. Reproduced from [94].

Other computational studies of MIP pre-polymerization systems have used similar methods to investigate monomer - template interactions to aid in the selection or optimization of polymer composition. The majority of these reports focused on selection of the functional monomer [104-136] but examples also include choice of solvent [119,137-140] and template [120,140-142]. In some instances, similar MD simulations of systems of 
limited complexity were employed in order to study putative monomer - template interactions [143-155] or to compare different stoichiometries [156-158].

The above type of MD-based studies of isolated MIP components or systems of limited size require relatively little computational cost and can provide valuable guidance to the composition of polymer systems. However, to obtain a more holistic view of the multitude of equilibria existing in pre-polymerization mixtures, and to reflect the polyclonality of non-covalent MIPs, simulations require the presence of multiple copies of template together with monomers (both functional and cross-linking) and solvent in relevant stoichiometries. These more comprehensive, all component MD simulations of MIP prepolymerization mixtures are highlighted in the following section.

\section{Simulations of all-component systems}

A combination of the inherent complexity of molecular imprinting systems and the limitations of computer power and software together long impeded the application of MD-based techniques to systems reflecting those used in the laboratory for polymer synthesis, i.e. with multiple copies of templates and corresponding stoichiometries for monomers, explicit solvent and initiator. The parallel developments in software and access to computing power made the first all-atom full system studies possible [41]. Today, the simulation of all-component systems with stoichiometries corresponding to experimental pre-polymerization mixtures is both possible, and quite readily accessible [159].

Essentially, MD-simulations of MIP pre-polymerization mixtures representative of synthetic protocols are undertaken after several equilibration steps, and the results of the production runs, effectively a temporal array of molecular trajectories, are subsequently analyzed, Figure 4a. Detailed information regarding the nature and extent of interactions between the molecular species can then be extracted and correlated with MIP recognition performance.

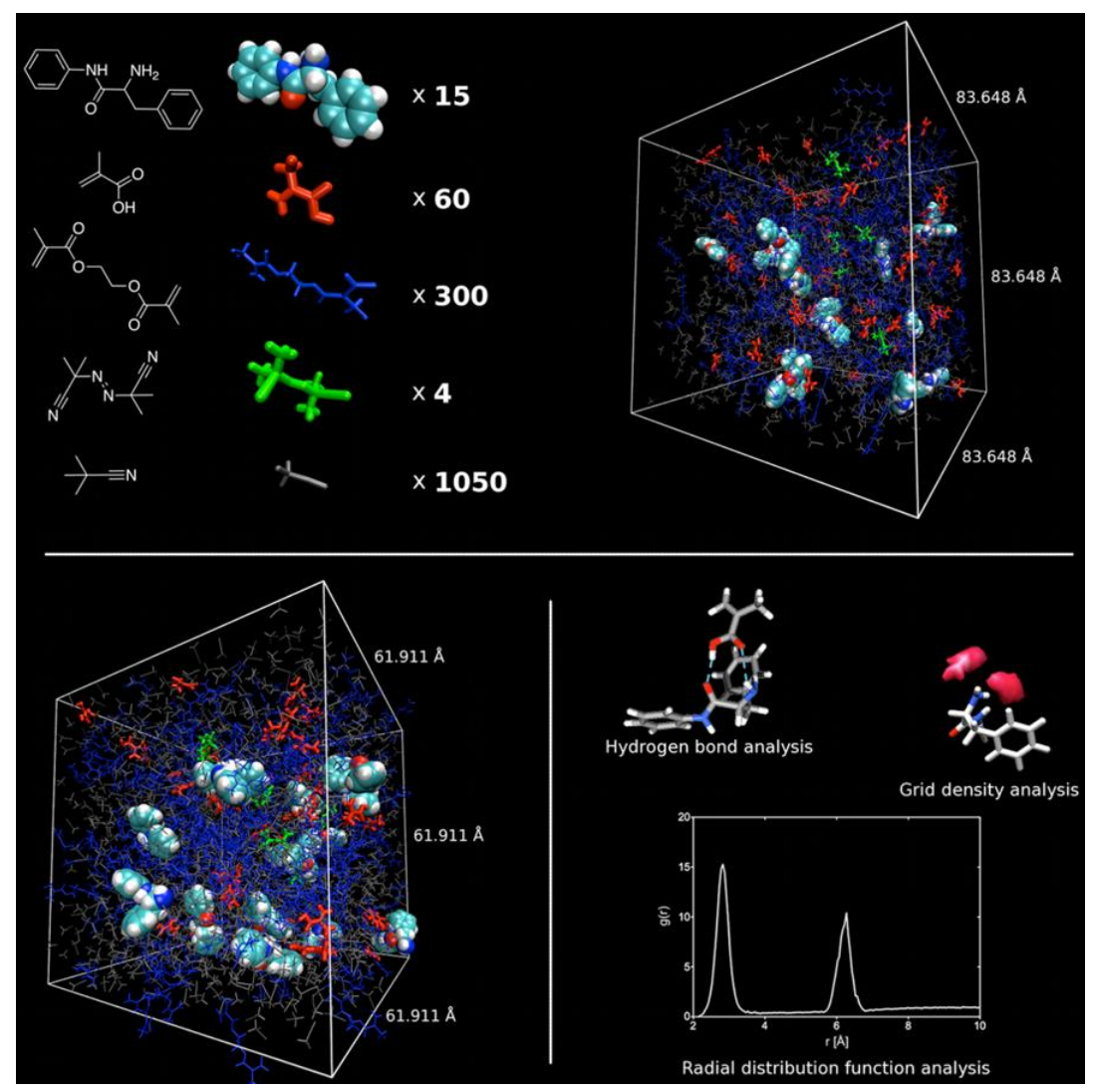

(a)

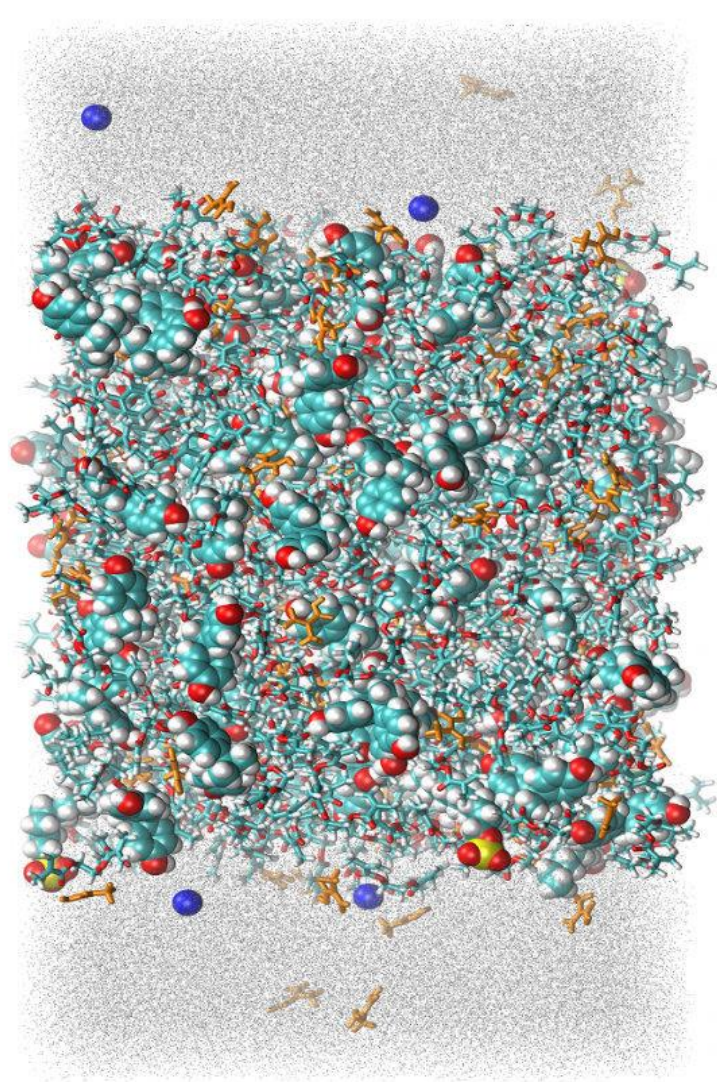

(b) 
Figure 4. Examples of all-atom, all-component simulation systems: (a) The components of a phenylalanine anilide imprinted polymer are randomly placed in a simulation box (top). After several equilibration steps (bottom left) the system is subjected to MD simulations, whereafter the resulting molecular trajectories are analyzed using e.g. radial distribution functions, hydrogen bond- and grid density analyses (bottom right). Reproduced from [41] with permission from Springer; (b) Snapshot from simulations of miniemulsion polymerization systems. Adapted from [160].

Several studies with the aim to explain the molecular basis of recognition have demonstrated the significance of including all the polymer building blocks in the simulation by illuminating the nature of complex formation and underlying mechanisms $[53,54,160-169]$. Some strategies involved the evaluation of the choice of suitable polymer components such as the type of functional monomer, crosslinker, template or porogen [170-176] and/or the investigation of the relative stoichiometries between the monomers $[172,175-188]$ suitable for use in imprinting protocols. A recent example by Rebelo et al. [183] reported the development of a MIP-based electrochemical sensor, comprised of a carbon paste electrode modified with MIP microparticles and multi-walled carbon nanotubes, for detection of the antibiotic furazolidone in environmental waters. The group employed MD simulation of six all-atom, all-component pre-polymerization mixtures to determine the most favorable template to monomer molar ratio to be used in the preparation of the sensor. Another comprehensive theoretical study was recently performed by Garcia and colleagues [184] using acrylate-based monomers in the design of nano-MIPs selective for L-fucose and D-mannose as prototype disease biomarkers. Here, MD simulations of fully atomistic pre-polymerization mixtures displaying various molar ratios between the monomers were performed to determine the most favorable composition to maximize recognition potential towards the templates

In a series of reports, Golker et al. [175,176,185-187] explored the relationships between MIP composition, final MIP morphology and recognition. By employing extensive MD simulations of pre-polymerization mixtures displaying a broad range of variations in composition and/or relative stoichiometry, correlations between the nature and extent of interactions observed in the pre-polymerization phase with results from physical characterization studies and equilibrium re-binding studies were described. Similar relationships between MIP composition, morphology and recognition were also investigated by Olsson et al. in a study of bisphenol A-imprinted nanoparticles synthesized by miniemulsion polymerization, Figure $4 \mathrm{~b}$ [160].

It is commonly accepted that monomer-template interactions in the pre-polymerization phase, if preserved during polymerization, represent the basis for recognition in MIPs, and as evident from the published literature reviewed here, MD simulations representing fully atomistic all-component MIP pre-polymerization mixtures have paved the way for a deeper understanding of the molecular events underlaying recognition. Nevertheless, multifaceted MD-based simulation approaches relating to other aspects of the imprinting process have been reported and are described in the following section.

\section{Simulations of MIP structure and function}

Since force-field based methods are unable to account for electron transfer necessary for bond formation, to date, naturally, most efforts on utilizing MD simulations in MIP development have been focused on modeling solution aspects prior to polymer gelation. Yet, a number of studies have attempted to model the polymerization reaction [189-194]. In a paper by Cowen et al. [193], a novel algorithm capable of mimicking atomistic radical polymerization of all-component pre-polymerization systems was presented. The usefulness and accuracy of the algorithm was demonstrated by simulating an ephedrine imprinted nanoparticle, Figure. 5a, and comparing the simulation data in terms of relative affinity and selectivity, prior to and after polymerization, with theoretical and empirical results derived from earlier studies [50]. Schauperl and Lewis [192] presented a polymer model to investigate aspects of binding heterogeneity of xanthine imprinted polymers. A growing chain of functional- and crosslinking monomers was formed by successively 
adding the monomers to the model system. As the monomer chain was allowed to grow around one or more template molecules up to a pre-defined density, MD simulations were utilized to study template-polymer interaction.

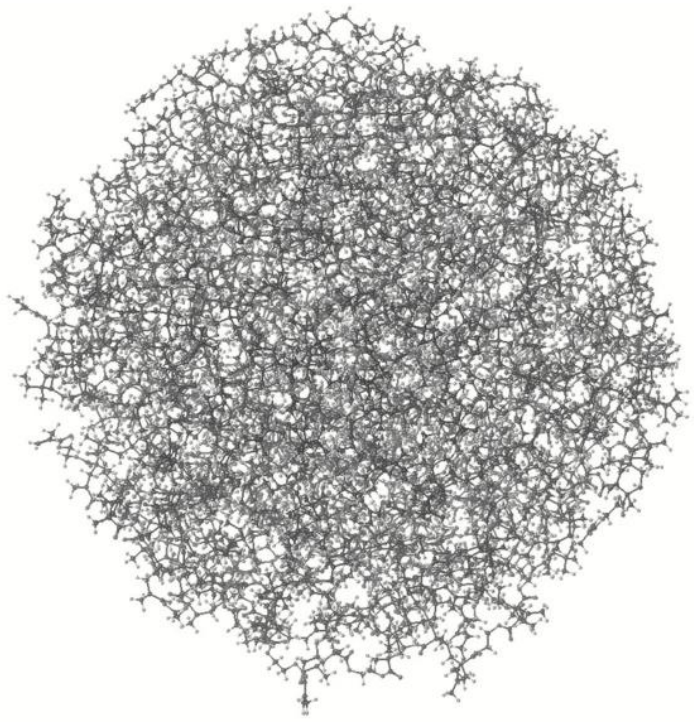

(a)

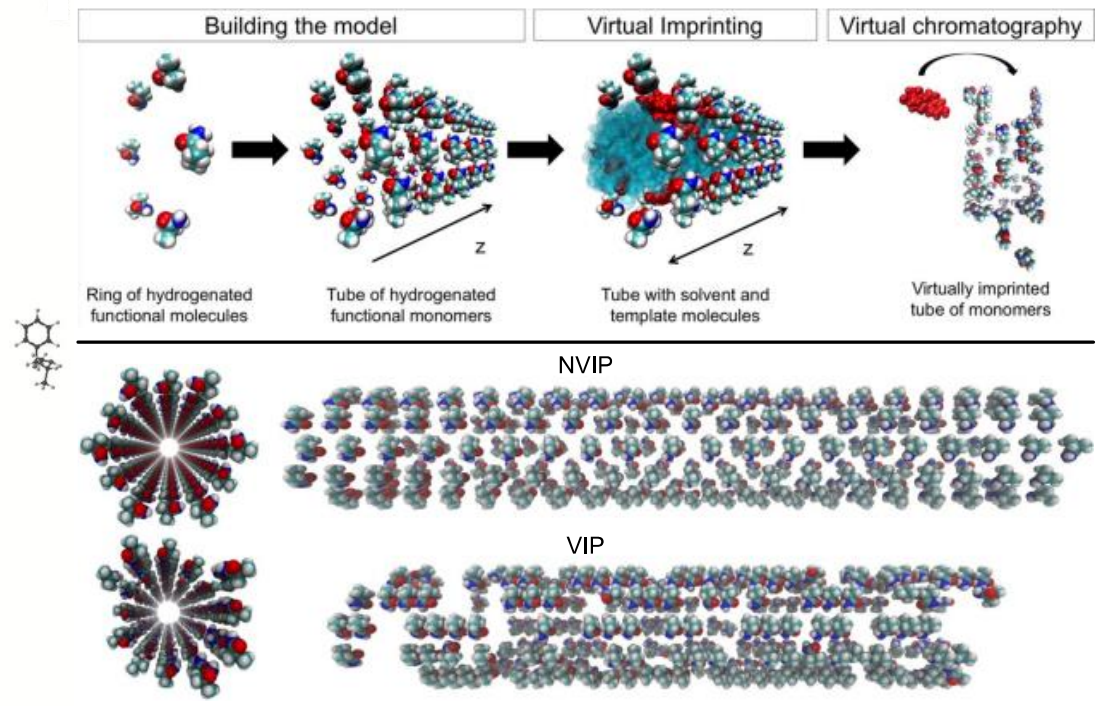

(b)

Figure 5. (a) Ephedrine imprinted nanoparticle resulting from the polymerization algorithm by Cowen et al. [193]. Reproduced with permission from John Wiley and Sons; (b) Construction of 17$\beta$-estradiol imprinted tubes for virtual chromatography (top). Inside and lateral views of the nonimprinted (NVIP) and virtually imprinted (VIP) tubes (bottom). Adapted from [195] with permission from the authors.

Attempts of using the MD method to model binding [195-207] and/or structural aspects [208-210] of the resulting polymer have been reported. In a study by Mizaikoff and co-workers [195], hollow tubes were created by sequential stacking of rings of functional monomers, Figure $5 \mathrm{~b}$. The inside void was then filled with solvent and template and the whole assembly subjected to MD simulations, allowing the monomers to move along the Z-axis. The resulting imprinted tubes were used for "virtual chromatography", again using MD simulations, by pushing solvent and template or analogues through the tubes.

With the aim of identifying factors underlying MIP affinity and selectivity, Sobiech and coworkers [198-200,203] employed a MD-based strategy to mimic binding site models. The method involved MD simulation of pre-arranged complexes between template, functional monomer and crosslinker whereafter the template was removed, and the polymerizing step mimicked by creation of new bonds between the vinyl groups of monomers and crosslinkers. The resulting cavity was then MD-simulated together with the analyte to model binding. A similar approach was used by Gajda et al. [201] to simulate a MIP binding site for aripiprazole, by Janczura et al. [204] to probe the adsorption behavior and selectivity of a MIP model for determination of nitroxidative stress products in human urine samples and by Zeng et al. [207] to simulate the adsorption process of a $\mathrm{pH}$ responsive switchable MIP cavity with affinity for tylosin, a diol-containing macrolide antibiotic. Mazouz and co-workers [202] utilized MD simulations to develop a binding model of a polypyrrol-based MIP sensor for detection of prostate specific antigen. In the study, monomer-template interactions in terms of adsorption energies were characterized and related to the ability of the polymer to generate imprinted binding sites for the protein. A coarse-grained simulation approach of protein imprinted hydrogels was presented by Zadok and Srebnik [210] where all-component MD simulations of pre-polymerization mixtures in combination with Monte Carlo methods were used to describe the effect of composition on template complexation and material characteristics 
Even though the calculations describing the intermolecular forces are based on classical Newtonian mechanics, hence providing simplified approximations of the molecular level events, the diversity of studies exploring the MD method to model the various stages of the imprinting process reflect the capability of the method to provide a holistic picture that can aid in the design of complex molecularly imprinted systems.

\section{Conclusions}

MD-based studies are having an increasing impact on the development of molecular imprinting science and technology. Since the introduction of MD-based fragment-screening-like studies of template-monomer interactions for monomer selection and subsequent full system simulations, MD-based studies, after successful benchmarking with experimental techniques, have found legitimacy as prognostic and diagnostic tools for the assessment of MIP systems. More recent years have even seen the application of MD for the prediction of MIP recognition and morphological properties and even MIP function. The ongoing improvements in computer power, software capabilities and understanding of the molecular imprinting process should reinforce the importance of in silico studies of MIP-systems, and in particular MD-based studies, over the coming years.

Funding: This research was funded by H2020-MSCA-ITN-2016, 722171-Biocapture; H2020FETOPEN-2018-2020, 829040-MindGAP and Stiftelsen för Kunskaps- och Kompetensutveckling (KKS), 2019-0045.

Data Availability Statement: Not applicable.

Acknowledgments: In this section, you can acknowledge any support given which is not covered by the author contribution or funding sections. This may include administrative and technical support, or donations in kind (e.g., materials used for experiments).

Conflicts of Interest: The authors declare no conflict of interest.

\section{References}

1. Wulff, G. Molecular Imprinting in Cross-Linked Materials with the Aid of Molecular Templates - A Way towards Artificial Antibodies. Angew. Chem. Int. Ed. 1995, 34, 1812-1832, doi:10.1002/anie.199518121.

2. Mosbach, K. Molecular imprinting. Trends Biochem. Sci 1994, 19, 9-14, doi:10.1016/0968-0004(94)90166-X.

3. Shea, K.J. Molecular imprinting of synthetic network polymers: The de novo synthesis of macromolecular binding and catalytic sites. Trends Polym. Sci. 1994, 2, 166-173.

4. Alexander, C.; Andersson, H.S.; Andersson, L.I.; Ansell, R.J.; Kirsch, N.; Nicholls, I.A.; O'Mahony, J.; Whitcombe, M.J. Molecular imprinting science and technology: A survey of the literature for the years up to and including 2003. J. Mol. Recognit. 2006, 19, 106-180, doi:10.1002/jmr.760.

5. Whitcombe, M.J.; Kirsch, N.; Nicholls, I.A. Molecular imprinting science and technology: a survey of the literature for the years 2004-2011. J. Mol. Recognit. 2014, 27, 297-401, doi:10.1002/jmr.2347.

6. Molecularly imprinted polymers: Man-made mimics of antibodies and their application in analytical chemistry. Sellergren, B., Ed.; Elsevier: Amsterdam, The Netherlands, 2001, ISBN:978-0444828378.

7. Komiyama, M.; Takeuchi, T.; Mukawa, T.; Asanuma, H. Molecular Imprinting: From Fundamentals to Applications; Wiley: Weinheim, Germany, 2002, ISBN:9783527602025.

8. Piletsky, S.; Turner, A. Molecular Imprinting of Polymers; CRC Press: Boca Raton, FL, USA, 2006, ISBN:9780429090349.

9. Molecularly Imprinted Materials: Science and Technology. Yan, M.; Ramström, O., Eds.; Marcel Dekker: New York, NY, USA, 2004, ISBN:978-0824753535.

10. Molecular Imprinting. Haupt, K., Ed.; Springer-Verlag: Berlin, Germany, 2012, ISBN:978-3642284205.

11. Molecular Imprinting: Principles and Applications of Micro- and Nanostructured Polymers. Ye, L., Ed.; Pan Stanford: Singapore, 2013, ISBN:978-981-4310-99-4.

12. Molecularly Imprinted Polymers: Methods and Protocols. Martín-Esteban, A., Ed.; Humana: New York, NY, USA, 2021, ISBN:9781-0716-1629-1.

13. Vlatakis, G.; Andersson, L.I.; Müller, R.; Mosbach, K. Drug assay using antibody mimics made by molecular imprinting. Nature 1993, 361, 645-647, doi:10.1038/361645a0.

14. Svenson, J.; Nicholls, I.A. On the thermal and chemical stability of molecularly imprinted polymers. Anal. Chim. Acta 2001, 435, 19-24, doi:10.1016/S0003-2670(00)01396-9. 
15. Sellergren, B. Noncovalent molecular imprinting: antibody-like molecular recognition in polymeric network materials. $\operatorname{Tr} A C$, Trends Anal. Chem. 1997, 16, 310-320, doi:10.1016/S0165-9936(97)00027-7.

16. Haupt, K.; Mosbach, K. Plastic antibodies: developments and applications. Trends Biotechnol. 1998, 16, 468-475, doi:10.1016/S0167-7799(98)01222-0.

17. Piletsky, S.A.; Alcock, S.; Turner, A.P.F. Molecular imprinting: at the edge of the third millennium. Trends Biotechnol. 2001, 19, 9-12, doi:10.1016/S0167-7799(00)01523-7.

18. Whitcombe, M.J.; Vulfson, E.N. Imprinted polymers. Adv. Mater. 2001, 13, 467-478, doi:10.1002/1521-4095(200104)13:7<467::Aidadma467>3.0.Co;2-t.

19. Turner, N.W.; Jeans, C.W.; Brain, K.R.; Allender, C.J.; Hlady, V.; Britt, D.W. From 3D to 2D: A Review of the Molecular Imprinting of Proteins. Biotechnol. Progr. 2006, 22, 1474-1489, doi:10.1021/bp060122g.

20. Whitcombe, M.J. Smart hydrogel crystal gardens. Nat. Chem. 2011, 3, 657-658, doi:10.1038/nchem.1125.

21. Whitcombe, M.J.; Chianella, I.; Larcombe, L.; Piletsky, S.A.; Noble, J.; Porter, R.; Horgan, A. The rational development of molecularly imprinted polymer-based sensors for protein detection. Chem. Soc. Rev. 2011, 40, 1547-1571, doi:10.1039/c0cs00049c.

22. Refaat, D.; Aggour, M.G.; Farghali, A.A.; Mahajan, R.; Wiklander, J.G.; Nicholls, I.A.; Piletsky, S.A. Strategies for Molecular Imprinting and the Evolution of MIP Nanoparticles as Plastic Antibodies-Synthesis and Applications. Int. J. Mol. Sci. 2019, 20, 6304 (article no.), doi:10.3390/ijms20246304.

23. Nicholls, I.A.; Wiklander, J.G. Towards Peptide and Protein Recognition by Antibody Mimicking Synthetic Polymers Background, State of the Art, and Future Outlook*. Aust. J. Chem. 2020, 73, 300-306, doi:10.1071/Ch20020.

24. SupelMIP Molecularly Imprinted Polymer SPE Cartridges. Availabe online: https://www.sigmaaldrich.com/SE/en/technicaldocuments/technical-article/analytical-chemistry/solid-phase-extraction/supelmip (accessed on 2022-01-07).

25. Robust synthetic antibodies for IVD - MIP Diagnostics. Availabe online: https://www.mip-dx.com/ (accessed on 2022-01-17).

26. Nicholls, I.A. Towards the rational design of molecularly imprinted polymers. J. Mol. Recognit. 1998, 11, 79-82, doi:10.1002/(SICI)1099-1352(199812)11:1/6<79::AID-JMR394>3.0.CO;2-B.

27. Nicholls, I.A. Thermodynamic Considerations for the Design of and Ligand Recognition by Molecularly Imprinted Polymers. Chem. Lett. 1995, 24, 1035-1036, doi:10.1246/cl.1995.1035.

28. Pande, V.S.; Grosberg, A.Y.; Tanaka, T. Thermodynamic procedure to synthesize heteropolymers that can renature to recognize a given target molecule. Proc. Natl. Acad. Sci. U. S. A. 1994, 91, 12976-12979, doi:10.1073/pnas.91.26.12976.

29. Umpleby Ii, R.J.; Bode, M.; Shimizu, K.D. Measurement of the continuous distribution of binding sites in molecularly imprinted polymers. Analyst 2000, 125, 1261-1265, doi:10.1039/B002354J.

30. Lanza, F.; Sellergren, B. Molecularly Imprinted Polymers via High-Throughput and Combinatorial Techniques. Macromol. Rapid Commun. 2004, 25, 59-68, doi:10.1002/marc.200300211.

31. Takeuchi, T.; Fukuma, D.; Matsui, J. Combinatorial Molecular Imprinting: An Approach to Synthetic Polymer Receptors. Anal. Chem. 1999, 71, 285-290, doi:10.1021/ac980858v.

32. Sellergren, B.; Lepistoe, M.; Mosbach, K. Highly enantioselective and substrate-selective polymers obtained by molecular imprinting utilizing noncovalent interactions. NMR and chromatographic studies on the nature of recognition. J. Am. Chem. Soc. 1988, 110, 5853-5860, doi:10.1021/ja00225a041.

33. Andersson, H.S.; Nicholls, I.A. Spectroscopic Evaluation of Molecular Imprinting Polymerization Systems. Bioorg. Chem. 1997, 25, 203-211, doi:10.1006/bioo.1997.1067.

34. Whitcombe, M.J.; Martin, L.; Vulfson, E.N. Predicting the selectivity of imprinted polymers. Chromatographia 1998, 47, 457-464, doi:10.1007/Bf02466481.

35. Adbo, K.; Andersson, H.S.; Ankarloo, J.; Karlsson, J.G.; Norell, M.C.; Olofsson, L.; Svenson, J.; Örtegren, U.; Nicholls, I.A. Enantioselective Tröger's Base Synthetic Receptors. Bioorg. Chem. 1999, 27, 363-371, doi:10.1006/bioo.1999.1136.

36. Nicholls, I.A.; Andersson, H.S.; Charlton, C.; Henschel, H.; Karlsson, B.C.G.; Karlsson, J.G.; O'Mahony, J.; Rosengren, A.M.; Rosengren, K.J.; Wikman, S. Theoretical and computational strategies for rational molecularly imprinted polymer design. Biosens. Bioelectron. 2009, 25, 543-552, doi:10.1016/j.bios.2009.03.038.

37. Nicholls, I.A.; Andersson, H.S.; Golker, K.; Henschel, H.; Karlsson, B.C.G.; Olsson, G.D.; Rosengren, A.M.; Shoravi, S.; Suriyanarayanan, S.; Wiklander, J.G.; Wikman, S. Rational design of biomimetic molecularly imprinted materials: theoretical and computational strategies for guiding nanoscale structured polymer development. Anal. Bioanal. Chem. 2011, 400, 1771-1786, doi:10.1007/s00216-011-4935-1.

38. Nicholls, I.A.; Andersson, H.S.; Golker, K.; Henschel, H.; Karlsson, B.C.G.; Olsson, G.D.; Rosengren, A.M.; Shoravi, S.; Wiklander, J.G.; Wikman, S. Rational Molecularly Imprinted Polymer Design: Theoretical and Computational Strategies. In Molecular Imprinting: Principles and Applications of Micro- and Nanostructured Polymers, Ye, L., Ed. Pan Stanford Publishing: Singapore, 2013; pp. 71-104, doi:10.1201/b15678.

39. Piletska, E.; Kumire, J.; Sergeyeva, T.; Piletsky, S. Rational design and development of affinity adsorbents for analytical and biopharmaceutical applications. J. Chin. Adv. Mater. Soc. 2013, 1, 229-244, doi:10.1080/22243682.2013.839207.

40. Subrahmanyam, S.; Karim, K.; Piletsky, S.A. Computational Approaches in the Design of Synthetic Receptors. In Designing Receptors for the Next Generation of Biosensors, Piletsky, S.A., Whitcombe, M.J., Eds. Springer-Verlag: Berlin, Germany, 2013; pp. 131-165, doi:10.1007/5346_2012_22. 
41. Nicholls, I.A.; Chavan, S.; Golker, K.; Karlsson, B.C.G.; Olsson, G.D.; Rosengren, A.M.; Suriyanarayanan, S.; Wiklander, J.G. Theoretical and Computational Strategies for the Study of the Molecular Imprinting Process and Polymer Performance. In Molecularly Imprinted Polymers in Biotechnology, Mattiasson, B., Ye, L., Eds. Springer International Publishing: Cham, Switzerland, 2015; pp. 25-50, doi:10.1007/10_2015_318.

42. Cowen, T.; Karim, K.; Piletsky, S. Computational approaches in the design of synthetic receptors - A review. Anal. Chim. Acta 2016, 936, 62-74, doi:10.1016/j.aca.2016.07.027.

43. Marć, M.; Kupka, T.; Wieczorek, P.P.; Namieśnik, J. Computational modeling of molecularly imprinted polymers as a green approach to the development of novel analytical sorbents. TrAC, Trends Anal. Chem. 2018, 98, 64-78, doi:10.1016/j.trac.2017.10.020.

44. Nicholls, I.A.; Olsson, G.D.; Karlsson, B.C.G.; Suriyanarayanan, S.; Wiklander, J.G. Theoretical and Computational Strategies in Molecularly Imprinted Polymer Development. In Molecularly Imprinted Polymers for Analytical Chemistry Applications, Kutner, W., Sharma, P.S., Eds. The Royal Society of Chemistry: Cambridge, UK, 2018; pp. 197-226, doi:10.1039/9781788010474-00197.

45. Chopra, I.; Rahangdale, D.; Kumar, A. Computational modeling for rational designing of imprinted polymers for herbicides: a review. Indian J. Agric. Sci. 2019, 89, 3-10.

46. Cowen, T.; Karim, K.; Piletsky, S.A. Chapter 3 - Modeling molecularly imprinted polymer mechanics. In Smart Polymer Catalysts and Tunable Catalysis, Li, S., Lieberzeit, P.A., Piletsky, S.A., Turner, A.P.F., Eds. Elsevier: Amsterdam, The Netherlands, 2019; pp. 51-75, doi:10.1016/B978-0-12-811840-5.00003-4.

47. Liu, Z.M.; Xu, Z.G.; Wang, D.; Yang, Y.M.; Duan, Y.L.; Ma, L.P.; Lin, T.; Liu, H.C. A Review on Molecularly Imprinted Polymers Preparation by Computational Simulation-Aided Methods. Polymers 2021, 13, 2657:1-2657:18, doi:10.3390/polym13162657.

48. Nicholls, I.A.; Golker, K.; Olsson, G.D.; Suriyanarayanan, S.; Wiklander, J.G. The Use of Computational Methods for the Development of Molecularly Imprinted Polymers. Polymers 2021, 13, 2841:1-2841:40, doi:10.3390/polym13172841.

49. Suryana, S.; Mutakin; Rosandi, Y.; Hasanah, A.N. An Update on Molecularly Imprinted Polymer Design through a Computational Approach to Produce Molecular Recognition Material with Enhanced Analytical Performance. Molecules 2021, 26, 1891:1-1891:20, doi:10.3390/molecules26071891.

50. Piletsky, S.A.; Karim, K.; Piletska, E.V.; Turner, A.P.F.; Day, C.J.; Freebairn, K.W.; Legge, C. Recognition of ephedrine enantiomers by molecularly imprinted polymers designed using a computational approach. Analyst 2001, 126, 1826-1830, doi:10.1039/b102426b.

51. Schneider, G.; Bohm, H.J. Virtual screening and fast automated docking methods. Drug Discovery Today 2002, 7, 64-70, doi:10.1016/s1359-6446(01)02091-8.

52. Erlanson, D.A.; Fesik, S.W.; Hubbard, R.E.; Jahnke, W.; Jhoti, H. Twenty years on: the impact of fragments on drug discovery. Nature Reviews Drug Discovery 2016, 15, 605-619, doi:10.1038/nrd.2016.109.

53. O'Mahony, J.; Karlsson, B.C.G.; Mizaikoff, B.; Nicholls, I.A. Correlated theoretical, spectroscopic and X-ray crystallographic studies of a non-covalent molecularly imprinted polymerisation system. Analyst 2007, 132, 1161-1168, doi:10.1039/b706258c.

54. Karlsson, B.C.G.; O'Mahony, J.; Karlsson, J.G.; Bengtsson, H.; Eriksson, L.A.; Nicholls, I.A. Structure and dynamics of monomer-template complexation: An explanation for molecularly imprinted polymer recognition site heterogeneity. J. Am. Chem. Soc. 2009, 131, 13297-13304, doi:10.1021/ja902087t.

55. Subrahmanyam, S.; Piletsky, S.A.; Piletska, E.V.; Chen, B.; Karim, K.; Turner, A.P.F. 'Bite-and-switch' approach using computationally designed molecularly imprinted polymers for sensing of creatinine. Biosens. Bioelectron. 2001, 16, 631-637, doi:10.1016/s0956-5663(01)00191-9.

56. Chianella, I.; Lotierzo, M.; Piletsky, S.A.; Tothill, I.E.; Chen, B.; Karim, K.; Turner, A.P.F. Rational design of a polymer specific for microcystin-LR using a computational approach. Anal. Chem. 2002, 74, 1288-1293, doi:10.1021/ac010840b.

57. Chianella, I.; Piletsky, S.A.; Tothill, I.E.; Chen, B.; Turner, A.P.F. MIP-based solid phase extraction cartridges combined with MIP-based sensors for the detection of microcystin-LR. Biosens. Bioelectron. 2003, 18, 119-127, doi:10.1016/s0956-5663(02)001653.

58. Piletska, E.; Piletsky, S.; Karim, K.; Terpetschnig, E.; Turner, A. Biotin-specific synthetic receptors prepared using molecular imprinting. Anal. Chim. Acta 2004, 504, 179-183, doi:10.1016/s0003-2670(03)00813-4.

59. Piletsky, S.; Piletska, E.; Karim, K.; Foster, G.; Legge, C.; Turner, A. Custom synthesis of molecular imprinted polymers for biotechnological application: Preparation of a polymer selective for tylosin. Anal. Chim. Acta 2004, 504, 123-130, doi:10.1016/S0003-2670(03)00814-6.

60. Turner, N.W.; Piletska, E.V.; Karim, K.; Whitcombe, M.; Malecha, M.; Magan, N.; Baggiani, C.; Piletsky, S.A. Effect of the solvent on recognition properties of molecularly imprinted polymer specific for ochratoxin A. Biosens. Bioelectron. 2004, 20, 1060-1067, doi:10.1016/j.bios.2004.06.052.

61. Piletska, E.V.; Romero-Guerra, M.; Chianella, I.; Karim, K.; Turner, A.P.F.; Piletsky, S.A. Towards the development of multisensor for drugs of abuse based on molecular imprinted polymers. Anal. Chim. Acta 2005, 542, 111-117, doi:10.1016/j.aca.2005.03.067.

62. Piletska, E.V.; Romero-Guerra, M.; Guerreiro, A.R.; Karim, K.; Turner, A.P.F.; Piletsky, S.A. Adaptation of the molecular imprinted polymers towards polar environment. Anal. Chim. Acta 2005, 542, 47-51, doi:10.1016/j.aca.2005.01.034.

63. Piletska, E.V.; Turner, N.W.; Turner, A.P.; Piletsky, S.A. Controlled release of the herbicide simazine from computationally designed molecularly imprinted polymers. J. Controlled Release 2005, 108, 132-139, doi:10.1016/j.jconrel.2005.07.016. 
64. Chianella, I.; Karim, K.; Piletska, E.V.; Preston, C.; Piletsky, S.A. Computational design and synthesis of molecularly imprinted polymers with high binding capacity for pharmaceutical applications-model case: Adsorbent for abacavir. Anal. Chim. Acta 2006, 559, 73-78, doi:10.1016/j.aca.2005.11.068.

65. Breton, F.; Rouillon, R.; Piletska, E.V.; Karim, K.; Guerreiro, A.; Chianella, I.; Piletsky, S.A. Virtual imprinting as a tool to design efficient MIPs for photosynthesis-inhibiting herbicides. Biosens. Bioelectron. 2007, 22, 1948-1954, doi:10.1016/j.bios.2006.08.017.

66. Guerreiro, A.; Soares, A.; Piletska, E.; Mattiasson, B.; Piletsky, S. Preliminary evaluation of new polymer matrix for solid-phase extraction of nonylphenol from water samples. Anal. Chim. Acta 2008, 612, 99-104, doi:10.1016/j.aca.2008.02.010.

67. Pascale, M.; De Girolamo, A.; Visconti, A.; Magan, N.; Chianella, I.; Piletska, E.V.; Piletsky, S.A. Use of itaconic acid-based polymers for solid-phase extraction of deoxynivalenol and application to pasta analysis. Anal. Chim. Acta 2008, 609, 131-138, doi:10.1016/j.aca.2008.01.004.

68. Piletska, E.V.; Villoslada, F.N.; Chianella, I.; Bossi, A.; Karim, K.; Whitcombe, M.J.; Piletsky, S.A.; Doucette, G.J.; Ramsdell, J.S. Extraction of domoic acid from seawater and urine using a resin based on 2-(trifluoromethyl)acrylic acid. Anal. Chim. Acta 2008, 610, 35-43, doi:10.1016/j.aca.2008.01.032.

69. Piletska, E.; Karim, K.; Coker, R.; Piletsky, S. Development of the custom polymeric materials specific for aflatoxin B1 and ochratoxin A for application with the ToxiQuant T1 sensor tool. J. Chromatogr. A 2010, 1217, 2543-2547, doi:10.1016/j.chroma.2009.11.091.

70. Piletska, E.V.; Stavroulakis, G.; Karim, K.; Whitcombe, M.J.; Chianella, I.; Sharma, A.; Eboigbodin, K.E.; Robinson, G.K.; Piletsky, S.A. Attenuation of Vibrio fischeri Quorum Sensing Using Rationally Designed Polymers. Biomacromolecules 2010, 11, 975-980, doi:10.1021/bm901451j.

71. Yañez, F.; Chianella, I.; Piletsky, S.A.; Concheiro, A.; Alvarez-Lorenzo, C. Computational modeling and molecular imprinting for the development of acrylic polymers with high affinity for bile salts. Anal. Chim. Acta 2010, 659, 178-185, doi:10.1016/j.aca.2009.11.054.

72. Gomez-Caballero, A.; Guerreiro, A.; Karim, K.; Piletsky, S.; Goicolea, M.A.; Barrio, R.J. Chiral imprinted polymers as enantiospecific coatings of stir bar sorptive extraction devices. Biosens. Bioelectron. 2011, 28, 25-32, doi:10.1016/j.bios.2011.06.048.

73. Piletska, E.V.; Stavroulakis, G.; Larcombe, L.D.; Whitcombe, M.J.; Sharma, A.; Primrose, S.; Robinson, G.K.; Piletsky, S.A. Passive Control of Quorum Sensing: Prevention of Pseudomonas aeruginosa Biofilm Formation by Imprinted Polymers. Biomacromolecules 2011, 12, 1067-1071, doi:10.1021/bm101410q.

74. Bakas, I.; Ben Oujji, N.; Moczko, E.; Istamboulie, G.; Piletsky, S.; Piletska, E.; Ait-Ichou, I.; Ait-Addi, E.; Noguer, T.; Rouillon, R. Molecular imprinting solid phase extraction for selective detection of methidathion in olive oil. Anal. Chim. Acta 2012, 734, 99105, doi:10.1016/j.aca.2012.05.013.

75. Muhammad, T.; Cui, L.; Jide, W.; Piletska, E.V.; Guerreiro, A.R.; Piletsky, S.A. Rational design and synthesis of water-compatible molecularly imprinted polymers for selective solid phase extraction of amiodarone. Anal. Chim. Acta 2012, 709, 98-104, doi:10.1016/j.aca.2011.10.009.

76. Muhammad, T.; Nur, Z.; Piletska, E.V.; Yimit, O.; Piletsky, S.A. Rational design of molecularly imprinted polymer: the choice of cross-linker. Analyst 2012, 137, 2623-2628, doi:10.1039/C2AN35228A.

77. Piletska, E.V.; Burns, R.; Terry, L.A.; Piletsky, S.A. Application of a Molecularly Imprinted Polymer for the Extraction of Kukoamine A from Potato Peels. J. Agric. Food. Chem. 2012, 60, 95-99, doi:10.1021/jf203669b.

78. Bakas, I.; Oujji, N.B.; Moczko, E.; Istamboulie, G.; Piletsky, S.; Piletska, E.; Ait-Addi, E.; Ait-Ichou, I.; Noguer, T.; Rouillon, R. Computational and experimental investigation of molecular imprinted polymers for selective extraction of dimethoate and its metabolite omethoate from olive oil. J. Chromatogr. A 2013, 1274, 13-18, doi:10.1016/j.chroma.2012.11.061.

79. Lakshmi, D.; Akbulut, M.; Ivanova-Mitseva, P.K.; Whitcombe, M.J.; Piletska, E.V.; Karim, K.; Güven, O.; Piletsky, S.A. Computational Design and Preparation of MIPs for Atrazine Recognition on a Conjugated Polymer-Coated Microtiter Plate. Ind. Eng. Chem. Res. 2013, 52, 13910-13916, doi:10.1021/ie302982h.

80. Piletska, E.V.; Karim, K.; Cutler, M.; Piletsky, S.A. Development of the protocol for purification of artemisinin based on combination of commercial and computationally designed adsorbents. J. Sep. Sci. 2013, 36, 400-406, doi:10.1002/jssc.201200520.

81. Sergeyeva, T.A.; Gorbach, L.A.; Piletska, E.V.; Piletsky, S.A.; Brovko, O.O.; Honcharova, L.A.; Lutsyk, O.D.; Sergeeva, L.M.; Zinchenko, O.A.; El'skaya, A.V. Colorimetric test-systems for creatinine detection based on composite molecularly imprinted polymer membranes. Anal. Chim. Acta 2013, 770, 161-168, doi:10.1016/j.aca.2013.01.048.

82. Bakas, I.; Ben Oujji, N.; Istamboulié, G.; Piletsky, S.; Piletska, E.; Ait-Addi, E.; Ait-Ichou, I.; Noguer, T.; Rouillon, R. Molecularly imprinted polymer cartridges coupled to high performance liquid chromatography (HPLC-UV) for simple and rapid analysis of fenthion in olive oil. Talanta 2014, 125, 313-318, doi:10.1016/j.talanta.2014.03.020.

83. Bakas, I.; Hayat, A.; Piletsky, S.; Piletska, E.; Chehimi, M.M.; Noguer, T.; Rouillon, R. Electrochemical impedimetric sensor based on molecularly imprinted polymers/sol-gel chemistry for methidathion organophosphorous insecticide recognition. Talanta 2014, 130, 294-298, doi:10.1016/j.talanta.2014.07.012.

84. Tsyrulneva, I.; Zaporozhets, O.; Piletska, E.; Piletsky, S. Molecular modelling and synthesis of a polymer for the extraction of amiloride and triamterene from human urine. Anal. Methods 2014, 6, 3429-3435, doi:10.1039/c4ay00318g.

85. Abdin, M.J.; Altintas, Z.; Tothill, I.E. In silico designed nanoMIP based optical sensor for endotoxins monitoring. Biosens. Bioelectron. 2015, 67, 177-183, doi:10.1016/j.bios.2014.08.009. 
86. Karim, K.; Giannoudi, L.; Piletska, E.; Chianella, I.; Henry, O.Y.F.; Laitenberger, P.; Piletsky, S.A.; Cowen, T. Development of MIP sensor for monitoring propofol in clinical procedures. J. Chin. Adv. Mater. Soc. 2015, 3, 149-160, doi:10.1080/22243682.2015.1031278.

87. Mistry, J.; Guerreiro, A.; Moczko, E.; Piletska, E.; Karim, K.; Piletsky, S.A. Analysis of cooperative interactions in molecularly imprinted polymer nanoparticles. Mol. Imprinting 2015, 3, 55-64, doi:10.1515/molim-2015-0003.

88. Piletska, E.V.; Abd, B.H.; Krakowiak, A.S.; Parmar, A.; Pink, D.L.; Wall, K.S.; Wharton, L.; Moczko, E.; Whitcombe, M.J.; Karim, K.; Piletsky, S.A. Magnetic high throughput screening system for the development of nano-sized molecularly imprinted polymers for controlled delivery of curcumin. Analyst 2015, 140, 3113-3120, doi:10.1039/c4an02292k.

89. Wren, S.P.; Piletsky, S.A.; Karim, K.; Gascoine, P.; Lacey, R.; Sun, T.; Grattan, K.T.V. Computational design and fabrication of optical fibre fluorescent chemical probes for the detection of cocaine. J. Lightwave Technol. 2015, 33, 2572-2579, doi:10.1109/Jlt.2015.2389036.

90. Altintas, Z.; Abdin, M.J.; Tothill, A.M.; Karim, K.; Tothill, I.E. Ultrasensitive detection of endotoxins using computationally designed nanoMIPs. Anal. Chim. Acta 2016, 935, 239-248, doi:10.1016/j.aca.2016.06.013.

91. Rodriguez-Dorado, R.; Carro, A.M.; Chianella, I.; Karim, K.; Concheiro, A.; Lorenzo, R.A.; Piletsky, S.; Alvarez-Lorenzo, C. Oxytetracycline recovery from aqueous media using computationally designed molecularly imprinted polymers. Anal. Bioanal. Chem. 2016, 408, 6845-6856, doi:10.1007/s00216-016-9811-6.

92. Aftim, N.; Istamboulié, G.; Piletska, E.; Piletsky, S.; Calas-Blanchard, C.; Noguer, T. Biosensor-assisted selection of optimal parameters for designing molecularly imprinted polymers selective to phosmet insecticide. Talanta 2017, 174, 414-419, doi:10.1016/j.talanta.2017.06.035.

93. Bates, F.; Busato, M.; Piletska, E.; Whitcombe, M.J.; Karim, K.; Guerreiro, A.; del Valle, M.; Giorgetti, A.; Piletsky, S. Computational design of molecularly imprinted polymer for direct detection of melamine in milk. Sep. Sci. Technol. 2017, 52, 1441-1453, doi:10.1080/01496395.2017.1287197.

94. Karim, K.; Cowen, T.; Guerreiro, A.; Piletska, E.; Whitcombe, M.J.; Piletsky, S.A. A Protocol for the Computational Design of High Affinity Molecularly Imprinted Polymer Synthetic Receptors. Glob. J. Biotechnol. Biomater. Sci. 2017, 3, 001-007, doi:10.17352/gjbbs.000009.

95. Piletska, E.V.; Pink, D.; Karim, K.; Piletsky, S.A. Development of a computationally-designed polymeric adsorbent specific for mycotoxin patulin. Analyst 2017, 142, 4678-4683, doi:10.1039/C7AN01294B.

96. Sergeyeva, T.; Yarynka, D.; Piletska, E.; Lynnik, R.; Zaporozhets, O.; Brovko, O.; Piletsky, S.; El'skaya, A. Fluorescent sen sor systems based on nanostructured polymeric membranes for selective recognition of Aflatoxin B1. Talanta 2017, 175, 101-107, doi:10.1016/j.talanta.2017.07.030.

97. Smolinska-Kempisty, K.; Ahmad, O.S.; Guerreiro, A.; Karim, K.; Piletska, E.; Piletsky, S. New potentiometric sensor based on molecularly imprinted nanoparticles for cocaine detection. Biosens. Bioelectron. 2017, 96, 49-54, doi:10.1016/j.bios.2017.04.034

98. Viveiros, R.; Karim, K.; Piletsky, S.A.; Heggie, W.; Casimiro, T. Development of a molecularly imprinted polymer for a pharmaceutical impurity in supercritical CO2: Rational design using computational approach. J. Cleaner Prod. 2017, 168, 10251031, doi:10.1016/j.jclepro.2017.09.026.

99. Musile, G.; Cenci, L.; Piletska, E.; Gottardo, R.; Bossi, A.M.; Bortolotti, F. Development of an in-house mixed-mode solid-phase extraction for the determination of 16 basic drugs in urine by High Performance Liquid Chromatography-Ion Trap Mass Spectrometry. J. Chromatogr. A 2018, 1560, 10-18, doi:10.1016/j.chroma.2018.05.019.

100. Esen, C.; Czulak, J.; Cowen, T.; Piletska, E.; Piletsky, S.A. Highly Efficient Abiotic Assay Formats for Methyl Parathion: Molecularly Imprinted Polymer Nanoparticle Assay as an Alternative to Enzyme-Linked Immunosorbent Assay. Anal. Chem. 2019, 91, 958-964, doi:10.1021/acs.analchem.8b04065.

101. Florea, A.; Cowen, T.; Piletsky, S.; De Wael, K. Electrochemical sensing of cocaine in real samples based on electrodeposited biomimetic affinity ligands. Analyst 2019, 144, 4639-4646, doi:10.1039/C9AN00618D.

102. Cruz, A.G.; Haq, I.; Cowen, T.; Di Masi, S.; Trivedi, S.; Alanazi, K.; Piletska, E.; Mujahid, A.; Piletsky, S.A. Design and fabrication of a smart sensor using in silico epitope mapping and electro-responsive imprinted polymer nanoparticles for determination of insulin levels in human plasma. Biosens. Bioelectron. 2020, 169, 112536:1-112536:7, doi:10.1016/j.bios.2020.112536.

103. Garcia-Cruz, A.; Cowen, T.; Voorhaar, A.; Piletska, E.; Piletsky, S.A. Molecularly imprinted nanoparticles-based assay (MINA) - detection of leukotrienes and insulin. Analyst 2020, 145, 4224-4232, doi:10.1039/D0AN00419G.

104. Pavel, D.; Lagowski, J. Computationally designed monomers and polymers for molecular imprinting of theophylline and its derivatives. Part I. Polymer 2005, 46, 7528-7542, doi:10.1016/j.polymer.2005.04.099.

105. Pavel, D.; Lagowski, J. Computationally designed monomers and polymers for molecular imprinting of theophylline-part II. Polymer 2005, 46, 7543-7556, doi:10.1016/j.polymer.2005.05.146.

106. Pavel, D.; Lagowski, J.; Lepage, C.J. Computationally designed monomers for molecular imprinting of chemical warfare agents - part V. Polymer 2006, 47, 8389-8399, doi:10.1016/j.polymer.2006.09.067.

107. Wei, S.; Jakusch, M.; Mizaikoff, B. Investigating the mechanisms of $17 \beta$-estradiol imprinting by computational prediction and spectroscopic analysis. Anal. Bioanal. Chem. 2007, 389, 423-431, doi:10.1007/s00216-007-1358-0.

108. Dong, C.; Li, X.; Guo, Z.; Qi, J. Development of a model for the rational design of molecular imprinted polymer: Computational approach for combined molecular dynamics/quantum mechanics calculations. Anal. Chim. Acta 2009, 647, 117-124, doi:10.1016/j.aca.2009.05.040. 
109. Li, Y.; Li, X.; Li, Y.; Dong, C.; Jin, P.; Qi, J. Selective recognition of veterinary drugs residues by artificial antibodies designed using a computational approach. Biomaterials 2009, 30, 3205-3211, doi:10.1016/j.biomaterials.2009.03.007.

110. Liu, R.; Li, X.; Li, Y.; Jin, P.; Qin, W.; Qi, J. Effective removal of rhodamine B from contaminated water using non-covalent imprinted microspheres designed by computational approach. Biosens. Bioelectron. 2009, 25, 629-634, doi:10.1016/j.bios.2009.01.039.

111. Hou, S.; Wang, Y.F.; Liu, N.; Liu, J. Preparation and recognition characteristics of thymopentin molecularly imprinted polymers on SiO2. Adsorpt. Sci. Technol. 2014, 32, 833-843, doi:10.1260/0263-6174.32.10.833.

112. Wang, C.L.; Hu, X.L.; Guan, P.; Qian, L.W.; Wu, D.F.; Li, J. Thymopentin magnetic molecularly imprinted polymers with room temperature ionic liquids as a functional monomer by surface-initiated ATRP. Int. J. Polym. Anal. Charact. 2014, 19, 70-82, doi:10.1080/1023666x.2014.864461.

113. Bitar, M.; Bou-Maroun, E.; Lerbret, A.; Ouaini, N.; Cayot, P. Binding characteristics of molecularly imprinted polymers based on fungicides in hydroalcoholic media. J. Sep. Sci. 2015, 38, 3607-3614, doi:10.1002/jssc.201500543.

114. Li, J.; Hu, X.L.; Guan, P.; Song, D.M.; Qian, L.W.; Du, C.B.; Song, R.Y.; Wang, C.L. Preparation of "dummy" L-phenylalanine molecularly imprinted microspheres by using ionic liquid as a template and functional monomer. J. Sep. Sci. 2015, 38, 3279-3287, doi:10.1002/jssc.201500539.

115. Wang, C.L.; Hu, X.L.; Guan, P.; Qian, L.W.; Wu, D.F.; Li, J. Superparamagnetic molecularly imprinting polymers for adsorbent and separation pentapeptides by surface ATRP. Sep. Sci. Technol. 2015, 50, 1768-1775, doi:10.1080/01496395.2014.980001.

116. Zhang, K.; Zou, W.Y.; Zhao, H.Y.; Dramou, P.; Pham-Huy, C.; He, J.; He, H. Adsorption behavior of a computer-aid designed magnetic molecularly imprinted polymer via response surface methodology. RSC Adv. 2015, 5, 61161-61169, doi:10.1039/c5ra10367c.

117. Chen, J.; Lewis, C.; Balamurugan, D.; Yang, Z.; Ai, L.; Cai, D. Theoretical analysis of a high performance protein imprint on a nanosensor. Sens. Bio-Sens. Res. 2016, 7, 12-19, doi:10.1016/j.sbsr.2015.11.009.

118. Douhaya, Y.V.; Barkaline, V.V.; Tsakalof, A. Computer-simulation-based selection of optimal monomer for imprinting of tri-Oacetyl adenosine in a polymer matrix: Calculations for benzene solution. J. Mol. Model. 2016, 22, 154:1-154:8, doi:10.1007/s00894016-3030-0.

119. Wang, Y.W.; Zhao, T.; Dai, P.; Jiang, N.; Li, F. Employment of molecularly imprinted polymers to high-throughput screen nNOS-PSD-95 interruptions: Structure and dynamics investigations on monomer-template complexation. ChemPhysChem 2016, 17, 893-901, doi:10.1002/cphc.201500941.

120. Xi, S.; Zhang, K.; Xiao, D.; He, H. Computational-aided design of magnetic ultra-thin dummy molecularly imprinted polymer for selective extraction and determination of morphine from urine by high-performance liquid chromatography. J. Chromatogr. A 2016, 1473, 1-9, doi:10.1016/j.chroma.2016.09.074.

121. Altintas, Z.; France, B.; Ortiz, J.O.; Tothill, I.E. Computationally modelled receptors for drug monitoring using an optical based biomimetic SPR sensor. Sens. Actuators, B 2016, 224, 726-737, doi:10.1016/j.snb.2015.10.075.

122. Li, G.Y.; Zhang, K.; Fizir, M.; Niu, M.C.; Sun, C.; Xi, S.L.; Hui, X.H.; Shi, J.R.; He, H. Rational design, preparation and adsorption study of a magnetic molecularly imprinted polymer using a dummy template and a bifunctional monomer. New J. Chem. 2017, 41, 7092-7101, doi:10.1039/c7nj00689f.

123. Niu, M.C.; Sun, C.; Zhang, K.; Li, G.Y.; Meriem, F.; Pham-Huy, C.; Hui, X.H.; Shi, J.R.; He, H. A simple extraction method for norfloxacin from pharmaceutical wastewater with a magnetic core-shell molecularly imprinted polymer with the aid of computer simulation. New J. Chem. 2017, 41, 2614-2624, doi:10.1039/c6nj03901d.

124. Saputra, A.; Wijaya, K.; Armunanto, R.; Tania, L.; Tahir, I. Determination of effective functional monomer and solvent for R(+)cathinone imprinted polymer using density functional theory and molecular dynamics simulation approaches. Indones. J. Chem. 2017, 17, 516-522, doi:10.22146/ijc.24311.

125. Eroglu, B.; Dalgakiran, D.; Inan, T.; Kurkcuoglu, O.; Guner, F.S. A computational and experimental approach to develop minocycline-imprinted hydrogels and determination of their drug delivery performances. J. Polym. Res. 2018, 25, 258:1-258:10, doi:10.1007/s10965-018-1647-7.

126. Fizir, M.; Wei, L.; Muchuan, N.; Itatahine, A.; Mehdi, Y.A.; He, H.; Dramou, P. QbD approach by computer aided design and response surface methodology for molecularly imprinted polymer based on magnetic halloysite nanotubes for extraction of norfloxacin from real samples. Talanta 2018, 184, 266-276, doi:10.1016/j.talanta.2018.02.056.

127. Nezammahalleh, H.; Mousavizadeh, S.H.; Babaeipour, V. New potentiometric sensor based on molecularly imprinted polymer for dipicolinic acid detection in aqueous media. IEEE Sens. J. 2018, 18, 7520-7528, doi:10.1109/Jsen.2018.2861706.

128. Paredes-Ramos, M.; Bates, F.; Rodríguez-González, I.; López-Vilariño, J.M. Computational approximations of molecularly imprinted polymers with sulphur based monomers for biological purposes. Mater. Today Commun. 2019, 20, 100526:1-100526:6, doi:10.1016/j.mtcomm.2019.05.002.

129. He, Q.; Liang, J.J.; Chen, L.X.; Chen, S.L.; Zheng, H.L.; Liu, H.X.; Zhang, H.J. Removal of the environmental pollutant carbamazepine using molecular imprinted adsorbents: Molecular simulation, adsorption properties, and mechanisms. Water Res. 2020, 168, 115164:1-115164:13, doi:10.1016/j.watres.2019.115164.

130. Wang, Y.F.; Ma, Y.; Zhou, J.J.; Su, K.H.; Zhang, B.L.; Zhang, Q.Y. Thermo-sensitive surface molecularly imprinted magnetic microspheres based on bio-macromolecules and their specific recognition of bovine serum albumin. J. Sep. Sci. 2020, 43, 9961002, doi:10.1002/jssc.201901024. 
131. Cubuk, H.; Ozbil, M.; Hatir, P.C. Computational analysis of functional monomers used in molecular imprinting for promising COVID-19 detection. Comput. Theor. Chem. 2021, 1199, 113215:1-113215:8, doi:10.1016/j.comptc.2021.113215.

132. Fernando, P.; Glasscott, M.W.; Kosgei, G.K.; Cobb, J.S.; Alberts, E.M.; Bresnahan, C.G.; Schutt, T.C.; George, G.W.; Moores, L.C. Toward Rational Design of Electrogenerated Molecularly Imprinted Polymers (eMIPs): Maximizing Monomer/Template Affinity. ACS Appl. Polym. Mater. 2021, 3, 4523-4533, doi:10.1021/acsapm.1c00575.

133. Li, X.T.; Wan, J.Q.; Wang, Y.; Ding, S.; Sun, J. Improvement of selective catalytic oxidation capacity of phthalates from surface molecular-imprinted catalysis materials: Design, mechanism, and application. Chem. Eng. J. 2021, 413, 127406:1-127406:10, doi:10.1016/j.cej.2020.127406.

134. Lopez, A.S.; Ramos, M.P.; Herrero, R.; Vilarino, J.M.L. Design, synthesis and HR - MAS NMR characterization of molecular imprinted polymers with emerging contaminants templates. Sep. Purif. Technol. 2021, 257, 117860:1-117860:7, doi:10.1016/j.seppur.2020.117860.

135. Yang, Y.Y.; Sun, X.; Hu, Q.; Yan, H.; Li, J.; Zhao, C.B.; Zuo, Z.Y. Molecularly imprinted solid-phase extraction of Chikusetsu saponin IVa from Panacis majoris Rhizoma. J. Sep. Sci. 2021, 44, 3665-3676, doi:10.1002/jssc.202100209.

136. Silva, C.F.; Menezes, L.F.; Pereira, A.C.; Nascimento, C.S. Molecularly Imprinted Polymer (MIP) for thiamethoxam: A theoretical and experimental study. J. Mol. Struct. 2021, 1231, 129980:1-129980:7, doi:10.1016/j.molstruc.2021.129980.

137. Liang, S.; Wan, J.; Zhu, J.; Cao, X. Effects of porogens on the morphology and enantioselectivity of core-shell molecularly imprinted polymers with ursodeoxycholic acid. Sep. Purif. Technol. 2010, 72, 208-216, doi:10.1016/j.seppur.2010.02.011.

138. Madikizela, L.M.; Mdluli, P.S.; Chimuka, L. Experimental and theoretical study of molecular interactions between 2-vinyl pyridine and acidic pharmaceuticals used as multi-template molecules in molecularly imprinted polymer. React. Funct. Polym. 2016, 103, 33-43, doi:10.1016/j.reactfunctpolym.2016.03.017.

139. Bird, L.; Herdes, C. The porogen effect on the complexation step of trinitrotoluene-methacrylic acid: Towards efficient imprinted polymer sensors. Mol. Syst. Des. Eng. 2018, 3, 89-95, doi:10.1039/c7me00084g.

140. Paredes-Ramos, M.; Sabin-Lopez, A.; Pena-Garcia, J.; Perez-Sanchez, H.; Lopez-Vilarino, J.M.; de Vicente, M.E.S. Computational aided acetaminophen - phthalic acid molecularly imprinted polymer design for analytical determination of known and new developed recreational drugs. J. Mol. Graphics Modell. 2020, 100, 107627:1-107627:8, doi:10.1016/j.jmgm.2020.107627.

141. Altintas, Z.; Takiden, A.; Utesch, T.; Mroginski, M.A.; Schmid, B.; Scheller, F.W.; Sussmuth, R.D. Integrated approaches toward high-affinity artificial protein binders obtained via computationally simulated epitopes for protein recognition. Adv. Funct. Mater. 2019, 29, 1807332:1-1807332:11, doi:10.1002/adfm.201807332.

142. Gomez-Arribas, L.N.; Darder, M.D.; Garcia, N.; Rodriguez, Y.; Urraca, J.L.; Moreno-Bondi, M.C. Hierarchically imprinted polymer for peptide tag recognition based on an oriented surface epitope approach. ACS Appl. Mater. Interfaces 2020, 12, 4911149121, doi:10.1021/acsami.0c14846.

143. Yoshida, M.; Hatate, Y.; Uezu, K.; Goto, M.; Furusaki, S. Chiral-recognition polymer prepared by surface molecular imprinting technique. Colloids Surf., A 2000, 169, 259-269, doi:10.1016/s0927-7757(00)00468-4.

144. Toorisaka, E.; Uezu, K.; Goto, M.; Furusaki, S. A molecularly imprinted polymer that shows enzymatic activity. Biochem. Eng. J. 2003, 14, 85-91, doi:10.1016/s1369-703x(02)00155-9.

145. Molinelli, A.; O'Mahony, J.; Nolan, K.; Smyth, M.R.; Jakusch, M.; Mizaikoff, B. Analyzing the mechanisms of selectivity in biomimetic self-assemblies via IR and NMR spectroscopy of prepolymerization solutions and molecular dynamics simulations. Anal. Chem. 2005, 77, 5196-5204, doi:10.1021/ac050525f.

146. Monti, S.; Cappelli, C.; Bronco, S.; Giusti, P.; Ciardelli, G. Towards the design of highly selective recognition sites into molecular imprinting polymers: A computational approach. Biosens. Bioelectron. 2006, 22, 153-163, doi:10.1016/j.bios.2006.05.017.

147. Wang, C.L.; Hu, X.L.; Guan, P.; Wu, D.F.; Qian, L.W.; Li, J.; Song, R.Y. Separation and purification of thymopentin with molecular imprinting membrane by solid phase extraction disks. J. Pharm. Biomed. Anal. 2015, 102, 137-143, doi:10.1016/j.jpba.2014.07.016.

148. Madikizela, L.M.; Zunngu, S.S.; Mlunguza, N.Y.; Tavengwa, N.T.; Mdluli, P.S.; Chimuka, L. Application of molecularly imprinted polymer designed for the selective extraction of ketoprofen from wastewater. Water SA 2018, 44, 406-418, doi:10.4314/wsa.v44i3.08.

149. Gore, P.M.; Khurana, L.; Siddique, S.; Panicker, A.; Kandasubramanian, B. Ion-imprinted electrospun nanofibers of chitosan/1butyl-3-methylimidazolium tetrafluoroborate for the dynamic expulsion of thorium (IV) ions from mimicked effluents. Environ. Sci. Pollut. Res. 2018, 25, 3320-3334, doi:10.1007/s11356-017-0618-6.

150. Wagner, S.; Zapata, C.; Wan, W.; Gawlitza, K.; Weber, M.; Rurack, K. Role of counterions in molecularly imprinted polymers for anionic species. Langmuir 2018, 34, 6963-6975, doi:10.1021/acs.langmuir.8b00500.

151. Cairo, P.; De Luca, G.; Tocci, E.; Drioli, E. 110th anniversary: Selective recognition of 5-fluorouracil with molecular imprinting membranes: Molecular details. Ind. Eng. Chem. Res. 2019, 58, 15497-15505, doi:10.1021/acs.iecr.9b02281.

152. Zhang, Y.Q.; Tan, X.; Liu, X.; Li, C.S.; Zeng, S.J.; Wang, H.; Zhang, S.J. Fabrication of multilayered molecularly imprinted membrane for selective recognition and separation of artemisinin. ACS Sustainable Chem. Eng. 2019, 7, 3127-3137, doi:10.1021/acssuschemeng.8b04908.

153. Xu, L.; Zhao, Z.X.; Huang, Y.A.; Zhu, Q.J. Preparation of chitosan molecularly imprinted polymers and the recognition mechanism for adsorption of alpha-lipoic acid. Molecules 2020, 25, 312:1-312:15, doi:10.3390/molecules25020312. 
154. Nguyen, H.T.; Bui, N.T.V.; Kanhounnon, W.G.; Huynh, K.L.V.; Nguyen, T.V.A.; Nguyen, H.M.; Do, M.H.; Badawi, M.; Thach, U.D. Co-precipitation polymerization of dual functional monomers and polystyrene-co-divinylbenzene for ciprofloxacin imprinted polymer preparation. RSC Adv. 2021, 11, 34281-34290, doi:10.1039/d1ra05505d.

155. Qu, Y.; Qin, L.; Yang, Y.Z.; Liu, X.G. Porous carbon nanosphere-based imprinted composite membrane for selective and effective separation of dibenzothiophene. Sep. Purif. Technol. 2021, 265, 118530:1-118530:14, doi:10.1016/j.seppur.2021.118530.

156. Kong, Y.; Wang, N.W.; Ni, X.N.; Yu, Q.Y.; Liu, H.; Huang, W.H.; Xu, W.Z. Molecular dynamics simulations of molecularly imprinted polymer approaches to the preparation of selective materials to remove norfloxacin. J. Appl. Polym. Sci. 2016, 133, 42817:1-42817:11, doi:10.1002/app.42817.

157. Liu, W.H.; Wang, J.; Yu, W.L.; Wang, X.H. Study on a biomimetic enzyme-linked immunosorbent assay for rapid detection of flumequine in animal foods. Food Anal. Methods 2020, 13, 403-411, doi:10.1007/s12161-019-01660-y.

158. Wang, D.; Yang, Y.; Xu, Z.G.; Liu, Y.J.; Liu, Z.M.; Lin, T.; Chen, X.L.; Liu, H.C. Molecular Simulation-Aided Preparation of Molecularly Imprinted Polymeric Solid-Phase Microextraction Coatings for Kojic Acid Detection in Wheat Starch and Flour Samples. Food Anal. Methods 2021, 14, 2076-2087, doi:10.1007/s12161-021-02039-8.

159. Olsson, G.D.; Wiklander, J.G.; Nicholls, I.A. Using Molecular Dynamics in the Study of Molecularly Imprinted Polymers. In Molecularly Imprinted Polymers: Methods and Protocols, Martín-Esteban, A., Ed. Humana: New York, NY, USA, 2021; pp. 241-268, doi:10.1007/978-1-0716-1629-1_21.

160. Olsson, G.D.; Niedergall, K.; Bach, M.; Karlsson, B.C.G.; Tovar, G.; Nicholls, I.A. Simulation of imprinted emulsion prepolymerization mixtures. Polym. J. 2015, 47, 827-830, doi:10.1038/pj.2015.63.

161. Cleland, D.; Olsson, G.D.; Karlsson, B.C.G.; Nicholls, I.A.; McCluskey, A. Molecular dynamics approaches to the design and synthesis of PCB targeting molecularly imprinted polymers: Interference to monomer-template interactions in imprinting of 1,2,3-trichlorobenzene. Org. Biomol. Chem. 2014, 12, 844-853, doi:10.1039/c3ob42399a.

162. O’Mahony, J.; Moloney, M.; McCormack, M.; Nicholls, I.A.; Mizaikoff, B.; Danaher, M. Design and implementation of an imprinted material for the extraction of the endocrine disruptor bisphenol A from milk. J. Chromatogr. B 2013, 931, 164-169, doi:10.1016/j.jchromb.2013.05.025.

163. Olsson, G.D.; Karlsson, B.C.G.; Schillinger, E.; Sellergren, B.; Nicholls, I.A. Theoretical studies of 17- $\beta$-estradiol-imprinted prepolymerization mixtures: Insights concerning the roles of cross-linking and functional monomers in template complexation and polymerization. Ind. Eng. Chem. Res. 2013, 52, 13965-13970, doi:10.1021/ie401115f.

164. Olsson, G.D.; Karlsson, B.C.G.; Shoravi, S.; Wiklander, J.G.; Nicholls, I.A. Mechanisms underlying molecularly imprinted polymer molecular memory and the role of crosslinker: Resolving debate on the nature of template recognition in phenylalanine anilide imprinted polymers. J. Mol. Recognit. 2012, 25, 69-73, doi:10.1002/jmr.2147.

165. Perez, M.; Concu, R.; Ornelas, M.; Cordeiro, M.; Azenha, M.; Silva, A.F. Measurement artifacts identified in the UV-vis spectroscopic study of adduct formation within the context of molecular imprinting of naproxen. Spectrochim. Acta, Part A 2016, 153, 661-668, doi:10.1016/j.saa.2015.10.005.

166. Schillinger, E.; Möder, M.; Olsson, G.D.; Nicholls, I.A.; Sellergren, B. An artificial estrogen receptor through combinatorial imprinting. Chem. - Eur. J. 2012, 18, 14773-14783, doi:10.1002/chem.201201428.

167. Shinde, S.; Incel, A.; Mansour, M.; Olsson, G.D.; Nicholls, I.A.; Esen, C.; Urraca, J.; Sellergren, B. Urea-based imprinted polymer hosts with switchable anion preference. J. Am. Chem. Soc. 2020, 142, 11404-11416, doi:10.1021/jacs.0c00707.

168. Shoravi, S.; Olsson, G.D.; Karlsson, B.C.G.; Nicholls, I.A. On the influence of crosslinker on template complexation in molecularly imprinted polymers: A computational study of prepolymerization mixture events with correlations to templatepolymer recognition behavior and NMR spectroscopic studies. Int. J. Mol. Sci. 2014, 15, 10622-10634, doi:10.3390/ijms150610622.

169. Concu, R.; Cordeiro, M.N.D.S. Molecular dynamics simulation study of the selectivity of a silica polymer for ibuprofen. Int. J. Mol. Sci. 2016, 17, 1083:1-1083:11, doi:10.3390/ijms17071083.

170. Henschel, H.; Kirsch, N.; Hedin-Dahlström, J.; Whitcombe, M.J.; Wikman, S.; Nicholls, I.A. Effect of the cross-linker on the general performance and temperature dependent behaviour of a molecularly imprinted polymer catalyst of a Diels-Alder reaction. J. Mol. Catal. B: Enzym. 2011, 72, 199-205, doi:10.1016/j.molcatb.2011.06.006.

171. Inan, T.; Dalgakiran, D.; Kurkcuoglu, O.; Guner, F.S. Elucidating doxycycline loading and release performance of imprinted hydrogels with different cross-linker concentrations: a computational and experimental study. J. Polym. Res. 2021, 28, 408:1408:19, doi:10.1007/s10965-021-02740-6.

172. Qiu, C.X.; Yang, W.M.; Zhou, Z.P.; Yan, Y.S.; Xu, W.Z. Rational design and preparation of dibenzothiophene-targeting molecularly imprinted polymers with molecular dynamics approaches and surface-initiated activators regenerated by electrontransfer atom-transfer radical polymerization. J. Appl. Polym. Sci. 2015, 132, 42629:1-42629:15, doi:10.1002/app.42629.

173. Shoravi, S.; Olsson, G.D.; Karlsson, B.C.G.; Bexborn, F.; Abghoui, Y.; Hussain, J.; Wiklander, J.G.; Nicholls, I.A. In silico screening of molecular imprinting prepolymerization systems: Oseltamivir selective polymers through full-system molecular dynamicsbased studies. Org. Biomol. Chem. 2016, 14, 4210-4219, doi:10.1039/c6ob00305b.

174. Rebelo, P.; Pacheco, J.G.; Voroshylova, I.V.; Cordeiro, M.; Delerue-Matos, C. Development of a molecular imprinted electrochemiluminescence sensor for amitriptyline detection: From MD simulations to experimental implementation. Electrochim. Acta 2021, 397, 139273:1-139273:11, doi:10.1016/j.electacta.2021.139273. 
175. Golker, K.; Karlsson, B.C.G.; Wiklander, J.G.; Rosengren, A.M.; Nicholls, I.A. Hydrogen bond diversity in the prepolymerization stage contributes to morphology and MIP-template recognition - MAA versus MMA. Eur. Polym. J. 2015, 66, 558-568, doi:10.1016/j.eurpolymj.2015.03.018.

176. Golker, K.; Olsson, G.D.; Nicholls, I.A. The influence of a methyl substituent on molecularly imprinted polymer morphology and recognition - Acrylic acid versus methacrylic acid. Eur. Polym. J. 2017, 92, 137-149, doi:10.1016/j.eurpolymj.2017.04.043.

177. Azenha, M.; Szefczyk, B.; Loureiro, D.; Kathirvel, P.; D. S. Cordeiro, M.N.; Fernando-Silva, A. Computational and experimental study of the effect of PEG in the preparation of damascenone-imprinted xerogels. Langmuir 2013, 29, 2024-2032, doi:10.1021/la304706t.

178. Daniels, E.; Mustafa, Y.L.; Herdes, C.; Leese, H.S. Optimization of Cortisol-Selective Molecularly Imprinted Polymers Enabled by Molecular Dynamics Simulations. ACS Applied Bio Mater. 2021, 4, 7243-7253, doi:10.1021/acsabm.1c00774.

179. Mamo, S.K.; Elie, M.; Baron, M.G.; Gonzalez-Rodriguez, J. Computationally designed perrhenate ion imprinted polymers for selective trapping of rhenium ions. ACS Appl. Polym. Mater. 2020, 2, 3135-3147, doi:10.1021/acsapm.0c00337.

180. Qiu, C.X.; Xing, Y.H.; Yang, W.M.; Zhou, Z.P.; Wang, Y.C.; Liu, H.; Xu, W.Z. Surface molecular imprinting on hybrid SiO2coated CdTe nanocrystals for selective optosensing of bisphenol A and its optimal design. Appl. Surf. Sci. 2015, 345, 405-417, doi:10.1016/j.apsusc.2015.03.150.

181. Wang, Y.C.; Wang, N.W.; Ni, X.N.; Jiang, Q.Q.; Yang, W.M.; Huang, W.H.; Xu, W.Z. A core-shell CdTe quantum dots molecularly imprinted polymer for recognizing and detecting p-nitrophenol based on computer simulation. RSC Adv. 2015, 5, 73424-73433, doi:10.1039/c5ra06889d.

182. Xu, W.; Wang, Y.; Huang, W.; Yu, L.; Yang, Y.; Liu, H.; Yang, W. Computer-aided design and synthesis of CdTe@SiO2 coreshell molecularly imprinted polymers as a fluorescent sensor for the selective determination of sulfamethoxazole in milk and lake water. J. Sep. Sci. 2017, 40, 1091-1098, doi:10.1002/jssc.201601180.

183. Rebelo, P.; Pacheco, J.G.; Voroshylova, I.V.; Melo, A.; Cordeiro, M.; Delerue-Matos, C. Rational development of molecular imprinted carbon paste electrode for Furazolidone detection: theoretical and experimental approach. Sens. Actuators, B 2021, 329, 129112:1-129112:11, doi:10.1016/j.snb.2020.129112.

184. Garcia, Y.; Usuga, B.A.; Campos, C.H.; Alderete, J.B.; Jimenez, V.A. NanoMIPs Design for Fucose and Mannose Recognition: A Molecular Dynamics Approach. J. Chem. Inf. Model. 2021, 61, 2048-2061, doi:10.1021/acs.jcim.0c01446.

185. Golker, K.; Karlsson, B.C.G.; Olsson, G.D.; Rosengren, A.M.; Nicholls, I.A. Influence of composition and morphology on template recognition in molecularly imprinted polymers. Macromolecules 2013, 46, 1408-1414, doi:10.1021/ma3024238.

186. Golker, K.; Karlsson, B.C.G.; Rosengren, A.M.; Nicholls, I.A. A functional monomer is not enough: Principal component analysis of the influence of template complexation in pre-polymerization mixtures on imprinted polymer recognition and morphology. Int. J. Mol. Sci. 2014, 15, 20572-20584, doi:10.3390/ijms151120572.

187. Golker, K.; Nicholls, I.A. The effect of crosslinking density on molecularly imprinted polymer morphology and recognition. Eur. Polym. J. 2016, 75, 423-430, doi:10.1016/j.eurpolymj.2016.01.008.

188. Herdes, C.; Sarkisov, L. Computer simulation of volatile organic compound adsorption in atomistic models of molecularly imprinted polymers. Langmuir 2009, 25, 5352-5359, doi:10.1021/la804168b.

189. Henthorn, D.B.; Peppas, N.A. Molecular simulations of recognitive polymer networks prepared by biomimetic configurational imprinting as responsive biomaterials. MRS Online Proc. Libr. 2003, 787, 7-15, doi:10.1557/PROC-787-G2.1.

190. Henthorn, D.B.; Peppas, N.A. Molecular simulations of recognitive behavior of molecularly imprinted intelligent polymeric networks. Ind. Eng. Chem. Res. 2007, 46, 6084-6091, doi:10.1021/ie0613691.

191. Huynh, T.P.; Wojnarowicz, A.; Sosnowska, M.; Srebnik, S.; Benincori, T.; Sannicolo, F.; D'Souza, F.; Kutner, W. Cytosine derivatized bis(2,2'-bithienyl)methane molecularly imprinted polymer for selective recognition of 6-thioguanine, an antitumor drug. Biosens. Bioelectron. 2015, 70, 153-160, doi:10.1016/j.bios.2015.03.001.

192. Schauperl, M.; Lewis, D.W. Probing the structural and binding mechanism heterogeneity of molecularly imprinted polymers. J. Phys. Chem. B 2015, 119, 563-571, doi:10.1021/jp506157x.

193. Cowen, T.; Busato, M.; Karim, K.; Piletsky, S.A. In silico synthesis of synthetic receptors: A polymerization algorithm. Macromol. Rapid Commun. 2016, 37, 2011-2016, doi:10.1002/marc.201600515.

194. Piletska, E.V.; Guerreiro, A.; Mersiyanova, M.; Cowen, T.; Canfarotta, F.; Piletsky, S.; Karim, K.; Piletsky, S. Probing peptide sequences on their ability to generate affinity sites in molecularly imprinted polymers. Langmuir 2020, 36, 279-283, doi:10.1021/acs.langmuir.9b3410.

195. Zink, S.; Moura, F.A.; Autreto, P.; Galvao, D.S.; Mizaikoff, B. Virtually imprinted polymers (VIPs): Understanding molecularly templated materials via molecular dynamics simulations. Phys. Chem. Chem. Phys. 2018, 20, 13145-13152, doi:10.1039/c7cp08284c.

196. Lv, Y.; Lin, Z.; Feng, W.; Zhou, X.; Tan, T. Selective recognition and large enrichment of dimethoate from tea leaves by molecularly imprinted polymers. Biochem. Eng. J. 2007, 36, 221-229, doi:10.1016/j.bej.2007.02.023.

197. Lv, Y.; Lin, Z.; Tan, T.; Feng, W.; Qin, P.; Li, C. Application of molecular dynamics modeling for the prediction of selective adsorption properties of dimethoate imprinting polymer. Sens. Actuators, B 2008, 133, 15-23, doi:10.1016/j.snb.2008.01.067.

198. Sobiech, M.; Zolek, T.; Lulinski, P.; Maciejewska, D. A computational exploration of imprinted polymer affinity based on voriconazole metabolites. Analyst 2014, 139, 1779-1788, doi:10.1039/c3an01721d. 
199. Sobiech, M.; Zolek, T.; Lulinski, P.; Maciejewska, D. Separation of octopamine racemate on (R,S)-2-amino-1-phenylethanol imprinted polymer - experimental and computational studies. Talanta 2016, 146, 556-567, doi:10.1016/j.talanta.2015.05.074.

200. Sobiech, M.; Lulinski, P.; Halik, P.; Maciejewska, D. The selective response of a templated polymer for the cationic drug pentamidine: Implications from molecular simulations and experimental data. RSC Adv. 2017, 7, 46881-46893, doi:10.1039/c7ra07590a.

201. Gajda, M.; Rybakiewicz, R.; Cieplak, M.; Zolek, T.; Maciejewska, D.; Gilant, E.; Rudzki, P.J.; Grab, K.; Kutner, A.; Borowicz, P.; Kutner, W.; Noworyta, K.R. Low-oxidation-potential thiophene-carbazole monomers for electro-oxidative molecular imprinting: Selective chemosensing of aripiprazole. Biosens. Bioelectron. 2020, 169, 112589:1-112589:10, doi:10.1016/j.bios.2020.112589.

202. Mazouz, Z.; Mokni, M.; Fourati, N.; Zerrouki, C.; Barbault, F.; Seydou, M.; Kalfat, R.; Yaakoubi, N.; Omezzine, A.; Bouslema, A.; Othmane, A. Computational approach and electrochemical measurements for protein detection with MIP-based sensor. Biosens. Bioelectron. 2020, 151, 111978:1-111978:8, doi:10.1016/j.bios.2019.111978.

203. Sobiech, M.; Giebultowicz, J.; Lulinski, P. Theoretical and experimental proof for selective response of imprinted sorbent analysis of hordenine in human urine. J. Chromatogr. A 2020, 1613, 460677:1-460677:13, doi:10.1016/j.chroma.2019.460677.

204. Janczura, M.; Sobiech, M.; Giebultowicz, J.; Lulinski, P. Computational and experimental designing of imprinted sorbent for the determination of nitroxidative stress products: an analysis of 4-hydroxyphenylacetic acid conversion. J. Mater. Sci. 2021, 56, 8439-8460, doi:10.1007/s10853-021-05847-9.

205. Jyoti; Gonzato, C.; Zolek, T.; Maciejewska, D.; Kutner, A.; Merlier, F.; Haupt, K.; Sharma, P.S.; Noworyta, K.R.; Kutner, W. Molecularly imprinted polymer nanoparticles-based electrochemical chemosensors for selective determination of cilostazol and its pharmacologically active primary metabolite in human plasma. Biosens. Bioelectron. 2021, 193, 113542:1-113542:9, doi:10.1016/j.bios.2021.113542.

206. Lu, J.; Qin, Y.-Y.; Wu, Y.-L.; Chen, M.-N.; Sun, C.; Han, Z.-X.; Yan, Y.-S.; Li, C.-X.; Yan, Y. Mimetic-core-shell design on molecularly imprinted membranes providing an antifouling and high-selective surface. Chem. Eng. J. 2021, 417, 128085:1128085:14, doi:10.1016/j.cej.2020.128085.

207. Zeng, H.N.; Yu, X.; Wan, J.F.; Cao, X.J. Synthesis of molecularly imprinted polymers based on boronate affinity for diolcontaining macrolide antibiotics with hydrophobicity-balanced and pH-responsive cavities. J. Chromatogr. A 2021, 1642, 461969:1-461969:11, doi:10.1016/j.chroma.2021.461969.

208. Zhao, Z.; Wang, Q.; Zhang, L.; Wu, T. Structured water and water-polymer interactions in hydrogels of molecularly imprinted polymers. J. Phys. Chem. B 2008, 112, 7515-7521, doi:10.1021/jp800836d.

209. Luo, D.; Zhao, Z.; Zhang, L.; Wang, Q.; Wang, J. On the structure of molecularly imprinted polymers by modifying charge on functional groups through molecular dynamics simulations. Mol. Simul. 2013, 40, 431-438, doi:10.1080/08927022.2013.819101.

210. Zadok, I.; Srebnik, S. Coarse-grained simulation of protein-imprinted hydrogels. J. Phys. Chem. B 2018, 122, 7091-7101, doi:10.1021/acs.jpcb.8b03774. 